\title{
Article
}

\section{Wellbeing: The Challenge of 'Operationalising' an Holistic Concept within a Reductionist Public Health Programme}

Dooris, Mark T, Farrier, Alan and Froggett, Lynn

Available at http://clok.uclan.ac.uk/18214/

Dooris, Mark T ORCID: 0000-0002-5986-1660, Farrier, Alan ORCID: 0000-00034989-2209 and Froggett, Lynn ORCID: 0000-0001-8406-6231 (2018) Wellbeing: The Challenge of 'Operationalising' an Holistic Concept within a Reductionist Public Health Programme. Perspectives in Public Health, 138 (2). pp. 93-99. ISSN 1757-9139

It is advisable to refer to the publisher's version if you intend to cite from the work. http://dx.doi.org/10.1177/1757913917711204

For more information about UCLan's research in this area go to http://www.uclan.ac.uk/researchgroups/ and search for <name of research Group>.

For information about Research generally at UCLan please go to http://www.uclan.ac.uk/research/

All outputs in CLoK are protected by Intellectual Property Rights law, including Copyright law. Copyright, IPR and Moral Rights for the works on this site are retained by the individual authors and/or other copyright owners. Terms and conditions for use of this material are defined in the policies page. 


\section{Article Type}

Original Research

Title:

Wellbeing: The Challenge of 'Operationalising' an Holistic Concept within a Reductionist Public Health Programme

\section{Word Count:}

3,989

\section{Authors:}

Mark Dooris Healthy and Sustainable Settings Unit, College of Health and Wellbeing, University of Central Lancashire, Brook Building, Preston PR1 2HE) - 01772893760 - mtdooris@uclan.ac.uk

Alan Farrier Healthy and Sustainable Settings Unit, College of Health and Wellbeing, University of Central Lancashire, Brook Building, Preston PR1 2HE) - 01772895118 - afarrier@uclan.ac.uk (Corresponding Author)

Lynn Froggett Psychosocial Research Unit, School of Social Work, Care and Community, University of Central Lancashire, Harrington Building, Preston PR1 2HE) - 01772893472 - Ifroggett@uclan.ac.uk

\section{Funding:}

This work was supported by the Big Lottery Fund [no Grant number].

Key Words:

Wellbeing, holism, reductionism, evaluation, qualitative research, public health 


\section{ABSTRACT}

Background

Wellbeing is a concept that, whilst contested, recognises individual and wider social, economic, political and environmental contextual influences - and is of growing interest and relevance locally and globally. In this paper, we report on one aspect of an evaluative research study conducted on a public health programme in North West England.

Aims

Within the context of a process evaluation that explored the delivery of a public health programme and sought to increase understanding of how and why different approaches worked well or not so well, this paper focuses specifically on the concept of wellbeing, examining perceptions of multiple stakeholders.

\section{Methods}

Interviews and focus groups were undertaken with 52 stakeholders involved in managing and facilitating the programme and its composite projects and with 90 community members involved as project participants. Data were subjected to thematic analysis, cross-check and refining.

\section{Findings}

Findings highlight stakeholders' diverse understandings of wellbeing, the complex relationship between health and wellbeing, and the perceived dissonance between the holistic concept of wellbeing and the reductionist design of the programme.

\section{Conclusions}

Wellbeing was understood to be 'more than health' and 'more than happiness', concerned with effective functioning, sense of purpose and flourishing. Essentially holistic, wellbeing offers opportunities to transcend clinical/pathogenic conceptions of 'health' and resonate with individuals, communities and local authorities. This raises concerns about how wellbeing can be meaningfully realised without compromising the concept, particularly when programmes are structured in reductionist ways requiring

monitoring against discrete outcomes. Implications for practice include: utilising wellbeing as a driver for cross-cutting public health in challenging economic and organisational contexts; acknowledging that wellbeing is essentially social as well as individual; appreciating that wellbeing is experienced in relation to contexts and surroundings; and recognising that wellbeing defined in terms of individual happiness risks compromising the future wellbeing of societies and the planet.

Pre-Print Version: Dooris, M., Farrier, A., Froggett, L. (in press) Wellbeing: The Challenge of 'Operationalising' an Holistic Concept within a Reductionist Public Health Programme. Perspectives in Public Health. 


\section{INTRODUCTION}

A concept of contemporary interest locally, nationally and globally (1), wellbeing remains highly contested (2). Traditionally two contrasting perspectives, hedonic and eudaemonic, have been identified - the former concerned with pleasure, avoidance of pain and subjective happiness; the latter focused on human flourishing and realisation of potential $(3,4)$. Walker $(5)$ reflects that, whereas the Romans equated concepts of health and wellbeing, the ancient Greeks distinguished between them - understanding good health to be a necessary, but not in itself sufficient, component of eudaemonic wellbeing. Similar perspectives emerged from discourses within $19^{\text {th }}$ century utilitarianism and $20^{\text {th }}$ century liberalism and socialism, which profiled an emphasis on wellbeing alongside and arguably beyond economic and material needs of individuals (6).

In 1946 the World Health Organisation defined health as a "complete state of physical, social and mental wellbeing" (7)(p1), thus catalysing a closely intertwined relationship between the two concepts. Seventy years later, wellbeing can be described as an emergent, though ascendant, concept in public health $(5,8)-$ one that focuses not only on individual lifestyle, but also on wider contextual determinants $(9,10)$. Arguing that health is only one component of wellbeing, McNaught (11) proposes a definitional framework comprising individual, family, community and society levels in dynamic relationship with people's circumstances, activities and resources. He also positions wellbeing as a "macro concept concerned with the objective and subjective assessment of how human beings survive, thrive and function" (p11). There is a growing critical discourse on the relationship between individual, collective and ecological wellbeing. This questions the degree to which the pursuit of personal wellbeing (particularly when defined in hedonic terms) threatens wellbeing of communities, societies and the ecosystems on which we depend (4). Jones-Devitt (12) extends this critique, questioning whether a commitment to wellbeing can be meaningfully realised within the context of a globalised neo-liberal ideology, which she suggests prioritises individual self-interest. Within England, the increasing use of wellbeing as a core concept within public health is related to a number of factors: the growing appreciation of mental health as a key focus (13); an understanding of the importance of objective and subjective elements (5); and the shift of public health to local authorities, which already have a 'Power to Promote Wellbeing' (14), alongside the establishment of health and wellbeing boards (15).

Pre-Print Version: Dooris, M., Farrier, A., Froggett, L. (in press) Wellbeing: The Challenge of 'Operationalising' an Holistic Concept within a Reductionist Public Health Programme. Perspectives in Public Health. 
In the context of this study, it is relevant to introduce notions of reductionism and holism and consider their application to wellbeing. Reductionism can be defined as "the practice of analysing and describing a complex phenomenon in terms of its simple or fundamental constituents," whilst holism is understood as "the theory that parts of a whole are in intimate interconnection, such that they cannot exist independently of the whole, or cannot be understood without reference to the whole, which is thus regarded as greater than the sum of its parts" (16). Although Carlisle et al. (4) contend that the concept of wellbeing can counter reductionist tendencies inherent in modernity, it is also clear that programmes may superficially appear to be holistic by addressing multiple health-related issues, but in reality operate in a disconnected and essentially reductionist way.

Target: Wellbeing (TWB) was a public health programme in North West England that ran from 2007 to 2015, funded by the Big Lottery Fund's Wellbeing Programme. This paper focuses on its first phase (2007-2012), which comprised a portfolio of twelve programmes. Reflecting the Wellbeing Programme's three stated outcomes, each programme consisted of a diversity of projects focused on healthy eating (e.g. food growing, cooking), increasing physical activity (e.g. walking, cycling) and mental wellbeing (e.g. drama activities, tailored support for refugees) $(17,18)$. There were 95 projects in total, benefiting over 110,000 people. Alongside a largely quantitative impact evaluation $(17,18)$, a process evaluation of TWB was commissioned as a freestanding study.

Whilst impact evaluation is essential to establish whether or not interventions, projects and programmes have worked, it does not address the questions of 'why' and 'how'. The process evaluation thus complemented the impact evaluation by conducting qualitative research to understand how the portfolio was delivered, by focusing on implementation, mechanisms of effect, and context (19). Its aim was to explore the design and delivery of TWB and increase understanding of how and why different approaches worked well or not so well in achieving desired outcomes. This paper focuses on one particular area explored through the evaluation the concept of wellbeing, examining perceptions of multiple stakeholders, including project participants, project staff and others involved at programme and portfolio management levels.

Pre-Print Version: Dooris, M., Farrier, A., Froggett, L. (in press) Wellbeing: The Challenge of 'Operationalising' an Holistic Concept within a Reductionist Public Health Programme. Perspectives in Public Health. 


\section{STUDY DESIGN AND METHODS}

Drawing on emergent models of wellbeing (11), the study was informed by a psychosocial perspective. This appreciates that individuals' experiences are influenced by interpersonal relationships, organisational contexts and wider social, political and economic systems (20) - highlights the interaction between people, settings and environments and seeks to understand multiple layers of determinants.

A qualitative approach was chosen, valuable for complementing quantitative research into wellbeing $(21,22)$ and appropriate for studying people within the context of organisations and communities and exploring meanings that people bring to their experiences and interactions (23). Appreciating the resource constraints involved in evaluating a large-scale portfolio, the process evaluation focused on a sample of 13 projects, chosen to ensure representation from the three focus themes and from three programmes (one each from the three sub-regions making up the TWB geographical footprint). Semi-structured interviews and focus groups were conducted, as was determined to be appropriate for the context (e.g. in projects that included participants with mild to moderate mental health issues, we gave the option to take part in a focus group or a one-to-one interview), revealing individual perspectives alongside insights informed by interaction (24).

A total of 142 stakeholders took part in 20 interviews and 29 focus groups, including 90 community members participating in projects, 40 staff involved in project and programme co-ordination and leadership, and 12 individuals responsible for portfolio-level governance. Data collection with project participants largely took place 'in situ', with researchers attending project sessions to help contextualise and strengthen authenticity of the process. Interview and focus group schedules were tailored to ensure applicability to each stakeholder group and covered a range of issues including project/programme initiation, development and sustainability; evaluation and administration; benefits of participation; and concepts of wellbeing. Questions pertaining to the latter, and therefore of particular pertinence to this paper, concerned use of models/frameworks, individual perceptions and the relationship between the three TWB outcome areas in the context of wellbeing. Interviews and focus groups were recorded and transcribed. Data were then subjected to manual thematic analysis, cross-check and refining, to build understanding through a process of discovering themes within the raw data, and by interpreting their implications in relation to the aims of the research (25). A University Ethics

Pre-Print Version: Dooris, M., Farrier, A., Froggett, L. (in press) Wellbeing: The Challenge of 'Operationalising' an Holistic Concept within a Reductionist Public Health Programme. Perspectives in Public Health. 
Committee granted approval for the evaluation. Key ethical issues were ensuring secure storage of confidential data (using password-protected and/or encrypted folders); and gaining informed consent to use selected quotations from interviews and focus groups (securing agreement to attribute quotations by generic role/title).

\section{FINDINGS}

Findings are structured under three themes: meanings of wellbeing; relationship between health and wellbeing; and dissonance between the holistic concept of wellbeing and the reductionist design of the programme.

\section{Meanings of wellbeing}

The research revealed a diversity of perceptions and understandings of 'wellbeing' among project participants. These ranged from straightforward functional definitions to more comprehensive descriptions highlighting a combination of objective and subjective assessments and emphasising material, psychological and social aspects:

[Wellbeing is]...being able to get up and get out and do things. (Project Participant \#1)

If you have no good accommodation, if you can't eat well, if you have no shelter, there is no wellbeing - if you lack these, your confidence may be knocked down. If you have nowhere to sleep - there is no way you can stand it. (Project Participant \#2)

Wellbeing is part of moving on basically. To get you into a situation where you feel part of things, to feel happy in your own skin, as well as being 'well'." (Project Participant \#3)

Staff also articulated a variety of definitions, appreciating the multi-faceted nature of the term, moving beyond superficial ideas of happiness and similarly highlighting multiple levels of influence:

If what this programme's about can be developing meaning and potential, then it's going to have a much longer lasting contribution. (Programme-Level Stakeholder \#1)

They enjoy the social aspect of it because a lot of them come every week, they've made new friends...obviously they've improved their health as well. (Project-Level Stakeholder \#1)

I see it as [concerning] the psychosocial dimension and putting that aspect firmly on the agenda. (PortfolioLevel Stakeholder \#1)

Pre-Print Version: Dooris, M., Farrier, A., Froggett, L. (in press) Wellbeing: The Challenge of 'Operationalising' an Holistic Concept within a Reductionist Public Health Programme. Perspectives in Public Health. 
There were differing views concerning how clearly the concept of wellbeing had been communicated and how important this was. Some staff involved in leading and managing the overall TWB portfolio knew that a conceptual model of wellbeing had been developed to inform Big Lottery's Wellbeing Programme. However, this did not seem to have explicitly informed programmes and projects:

I don't think there's been much articulation of what wellbeing is in its holistic sense, from my perspective anyway...[no] strong leadership that's stood up and said, 'this is what the programme is all about and it is about wellbeing'. (Portfolio-Level Stakeholder \#2)

Although some interviewees drew attention to frameworks such as the Five Ways to Wellbeing (26), others argued that a consistent and unified approach to conceptualising and articulating wellbeing was not important:

I'm not sure a single model or framework would have materially affected the way in which individual programmes or projects were implemented, because largely the characteristics of wellbeing are fairly well understood generically by people...I'm sure it needed quite a pragmatic approach rather than having a detailed conceptual understanding. (Portfolio-Level Stakeholder \#3)

\section{Relationship between health and wellbeing}

Interviewees viewed wellbeing as a term that, although often used interchangeably with health, also reflected a broader-based concept. Whilst encompassing 'health', it was seen also to underpin and incorporate a range of other aspects:

A lot of the definitions of wellbeing [include] the notion of how you feel and how you function [which]...is influenced by a whole range of factors and, in turn, influences a whole range of factors, of which your health...is one, but also your ability to be productive at work, find a job, education, it underpins all of those. (Portfolio-Level Stakeholder \#4)

I think the understanding on the ground [is that] wellbeing is part of a wider sphere and not just about health, that it actually permeates a lot of different things. (Project-Level Stakeholder \#2)

Extending this thinking, there was a strong sense that the term 'wellbeing' had been important in distinguishing TWB projects from more conventional work embodying medicalised understandings of 'health'. Interviewees saw the latter as focusing primarily on illness and absence of disease, but understood wellbeing to be a positive and complex concept focused on the whole person and their experiences, integrating physical, 
mental and social dimensions, and connecting people with their contexts. The term was thus understood to have been valuable in breaking down barriers and engaging people in activities that went beyond traditional boundaries of National Health Service (NHS)-led 'health' projects:

Having it under the heading of wellbeing makes it applicable to everybody and not stigmatised.

(Programme-Level Stakeholder \#2)

When you say health to somebody on the street, they think of health treatment but when you say wellbeing, people understand that more in terms of 'it's everything': it's where I live, what I do, what I eat, how I move around, my environment. I think that's much more helpful for a public health unit than the [traditional] definition of health. (Programme-Level Stakeholder \#3)

They're not coming to us to get fit or to reduce stress, they're just coming because they want to do gardening...So it's quite nice that you don't feel that you're delivering a sort of 'health-related' activity, you're delivering something that they want to do. (Project-Level Stakeholder \#3)

Reflecting on the use of wellbeing in the programme title, the breadth of the concept was viewed by some as an opportunity and by others as a challenge:

I think it's been really helpful that it has been called 'wellbeing'...that that's been the regional take on it."

(Programme-Level Stakeholder \#3)

Once you talk to an individual about their wellbeing, you've got a hundred million different takes on what that is...So in that sense, I think wellbeing was a difficult title concept." (Portfolio-Level Stakeholder \#5) Exploring this further, one staff member suggested the choice of term could be an attempt to distinguish TWB from mainstream health service responsibilities:

Perhaps there's something around the fact that Big Lottery Funding wasn't supposed to be seen as funding core things around health that the NHS should be doing. I mean maybe they came at it from that perspective. (Portfolio-Level Stakeholder \#4)

Echoing this, another stressed resonance with local authority functions and suggested that the concept of wellbeing is in the ascendancy, with a growing acceptance and widening understanding:

I think wellbeing has been seen as what is more done through local authorities and less through the NHS because there were duties given to local authorities around wellbeing...I think there's a very exciting agenda around Health and Wellbeing Boards... When it started, I think it was a difficult concept...but I think it's coming into its own now. (Portfolio-Level Stakeholder \#6)

Pre-Print Version: Dooris, M., Farrier, A., Froggett, L. (in press) Wellbeing: The Challenge of 'Operationalising' an Holistic Concept within a Reductionist Public Health Programme. Perspectives in Public Health. 


\section{Dissonance between the holistic concept of wellbeing and the reductionist design of the programme}

As detailed above, Big Lottery's Wellbeing Programme focused on physical activity, healthier eating and mental wellbeing - with projects being required to report against one primary theme for the purpose of monitoring and impact evaluation. Whilst not doubting the importance of these outcome areas, interviewees questioned the rationale for structuring a wellbeing programme in this way, highlighting a perceived dissonance between this compartmentalised approach and their broad-based understanding of the concept. Specifically, this distinction between themes did not sit easily with the 'joined-up' experience of wellbeing described by project participants and the holistic understanding that informed and infused programmes and projects:

It's all connected...If you get your diet wrong it's going to affect [your] emotional wellbeing. (Project Participant \#4)

We had the three themes... but overall it was general wellbeing wasn't it? I thought of it as being the whole, encompassing the whole. (Programme-Level Stakeholder \#4)

I know that we had the three key areas...And it was interesting...the number [of projects]...that actually recognised that wellbeing is made up of more than one thing and most of them recognised that their projects actually ticked more than one box. (Portfolio-Level Stakeholder \#7)

Whilst some staff noted benefits to structuring the portfolio around three themes, there was also regret at the 'missed opportunity' to do something more innovative, whereby projects and programmes explicitly explored wellbeing holistically:

A thing we were keen on at the beginning was looking at wellbeing as a whole issue, where a project would work on all three themes... [Yet] we ended up with 90-odd separate projects doing one of these three strands. (Portfolio-Level Stakeholder \#1)

Furthermore, it was clear that even when projects started with a single thematic emphasis, they often went on to develop a more connected and cross-cutting understanding of wellbeing:

Some of our projects have been initially 'just physical activity' or 'just food', but actually they've grown into looking at wellbeing... as a whole. (Programme-Level Stakeholder \#3)

Pre-Print Version: Dooris, M., Farrier, A., Froggett, L. (in press) Wellbeing: The Challenge of 'Operationalising' an Holistic Concept within a Reductionist Public Health Programme. Perspectives in Public Health. 
Echoing this, project participants revealed how projects provided benefits beyond their identified thematic focus and highlighted a growing awareness of how connectedness with other people and with the environment and natural world enriched their experience:

Having made your way to the park, you get to meet up with friends, all the troubles of the world seem lifted from your shoulders and you go home feeling uplifted... We get to see nature together as a group...[and] I feel much more confident as a cyclist. (Project Participant \#5)

There's green parts of Oldham that I never knew existed until I started doing these walks to be honest with you. (Project Participant \#6)

Programme managers explained that neither they nor their project managers found it easy to categorise the projects into a single 'box', raising questions about the usefulness of designating a priority outcome area for each project:

We tried to get a balance between all the three. Some of the organisations were already working with a notion of wellbeing that blurred the boundaries between these themes, the whole holistic picture.

(Programme-Level Stakeholder \#5)

There was thus a consensus that many projects naturally straddled and incorporated all three themes within a broad-based focus on wellbeing. Consequently, many cross-cutting projects were categorised for convenience under a priority outcome that did not readily match its full range of activities or aspirations. This appreciation naturally resulted in discontent about the value of the quantitative impact evaluation in capturing the real changes to people's lives:

We should say to the Big Lottery... what difference is being made, what's the real value of the money itself, the difference it makes to people's lives? That's what needs to be captured as opposed to numbers... The transformation part is what we're all about, socially as well as in terms of health benefits: it is the real reason why we're doing things isn't it? (Programme-Level Stakeholder \#6)

\section{DISCUSSION}

Reflecting on limitations, it could be argued that the study would have been stronger if those commissioning the process evaluation had integrated it with the impact evaluation. However, working within this constraint and with available resources, it used interviews and focus groups with a sample of projects and programmes

Pre-Print Version: Dooris, M., Farrier, A., Froggett, L. (in press) Wellbeing: The Challenge of 'Operationalising' an Holistic Concept within a Reductionist Public Health Programme. Perspectives in Public Health. 
from the TWB portfolio to generate a wealth of rich data concerning perceptions and understandings of multiple stakeholders.

Findings support wider literature $(8,12,27)$ in suggesting that wellbeing remains ill-defined, overlaid with diverse and subjective understandings. Some staff members felt that the concept was well-understood; however, others expressed concern that the diversity of understandings made the term challenging to use coherently. They also questioned why the model presented in a Wellbeing Programme report (21) was not articulated more widely. However, alongside this, the study revealed a strong belief that the language of wellbeing was enormously valuable in distancing TWB from narrow medicalised understandings of health and enabling project managers to engage participants effectively. This finding contrasts with the claim that wellbeing muddies rather than clarifies the concept of health (28). Importantly, though, it reflects a shift towards salutogenesis (29): this involves focusing not only on wider determinants of illness, but also on fostering health potentials and supporting human flourishing (30). It also echoes a vision of wellbeing as a new driver for public health policy and action, and as a unifying framework for disparate social policy, able to move beyond the traditional disease focus attached to the term 'health' and engage with the breadth of local government functions (31). In the English context, characterised by public health relocating to local authorities and health and wellbeing boards being established (15), the perceived resonance of wellbeing with local government becomes particularly salient (32).

The data highlighted multiple levels, signalling an appreciation that wellbeing is not only an individual experience but also a social and societal phenomenon. This was accompanied by a concern to understand the concept in relation to wider contextual and environmental influences. Whilst findings revealed both hedonic and eudaemonic perspectives (3), the latter dominated discourses of both staff and project participants. Staff talked about the importance of how people feel and function and emphasised that by prioritising meaning and potential, TWB projects and programmes will have longer-lasting value. Although participants often mentioned pleasure gained from projects, they also revealed understandings that ranged from a focus on provision of basic needs - elsewhere understood as prerequisites for health (33) - to a cross-cutting and eudaemonic focus on purpose and identity, referring to self-development, self-realisation and a renewed

Pre-Print Version: Dooris, M., Farrier, A., Froggett, L. (in press) Wellbeing: The Challenge of 'Operationalising' an Holistic Concept within a Reductionist Public Health Programme. Perspectives in Public Health. 
sense of direction. This echoes Ryan and Deci (3), who suggest that feelings of happiness do not constitute wellbeing, and accords with the views of writers who contend that what matters is not only the experience of positive emotions, but effective and authentic functioning within the context of society $(4,34)$.

There was widespread understanding that the concept of wellbeing is unruly and cross-cutting and essentially characterised by holism, supporting wider arguments (22). This meant that despite the requirement from Big Lottery as funders for projects to prioritise one defined outcome, staff working on TWB projects largely rejected this reductionist approach and felt unable to adhere to this neat 'compartmentalisation'. For example, 'healthy eating' cooking projects supported participants' mental wellbeing through the development of friendships; 'physical activity' cycling projects developed a sense of camaraderie and increased participants' awareness of their connection to their surroundings; and 'allotment-based' projects primarily focused on mental wellbeing enhanced awareness of healthy food, increased physical activity and supported positive flourishing associated with social contact and connecting with nature. Reflecting on the requirement to allocate projects to one primary theme, staff critiqued the impact evaluation as too prescriptive and linear. They suggested that its design failed to appreciate the complexities and synergies associated with wellbeing, and therefore to capture the full 'added value' of participation in TWB. They thus echoed Crawshaw (35) who cautions against assuming that wellbeing can have quantifiable measurable outcomes. There was consensus that the process evaluation went some way to addressing these concerns, enabling the more elusive elements of wellbeing to be articulated and revealing the programme's transformative potential.

\section{CONCLUSION}

This study supported wider literature, highlighting that wellbeing is a contested, multi-dimensional and complex phenomenon. There was consensus that wellbeing is 'more than health', a broader-based concept comprising multiple facets of human experience. Despite the popular conflation of the notions, it was also understood to represent 'more than happiness', with stakeholders emphasising eudaemonic perspectives and ideas relating to human flourishing. The research revealed a belief that the concept of wellbeing is holistic and offers the power to transcend clinical and pathogenic conceptions of 'health' and more fully engage and

Pre-Print Version: Dooris, M., Farrier, A., Froggett, L. (in press) Wellbeing: The Challenge of 'Operationalising' an Holistic Concept within a Reductionist Public Health Programme. Perspectives in Public Health. 
resonate with individuals, communities and local authorities. Linked to this, the study raised concerns about the feasibility of 'operationalising' wellbeing without compromising the concept, and questioned the value of funders categorising projects according to discrete thematic outcome areas. It was suggested that this oversimplification represents a reductionist approach that conflicts with the essentially 'whole' nature of wellbeing. There was also a sense that it failed to 'push the boundaries' of public health; interviewees suggested that the programme could instead have encouraged cross-cutting projects that tackled underlying determinants of wellbeing in joined-up innovative ways. Furthermore, the resulting 'linear' approach to monitoring may jeopardise evaluation by failing to capture impacts that cut across different themes and thus reveal the transformational role of projects in promoting wellbeing.

Despite these critical perspectives, it is important to celebrate positive impacts achieved by TWB. Looking ahead, there are a number of important themes emerging from the wider literature that resonate with the research findings. Firstly, public health can use wellbeing as a driver for policy and action by engaging with the breadth of local government functions (31). Within England, this is facilitated by the relocation of public health to local authorities, but also made enormously challenging by the economic context and swingeing cuts to core budgets - estimated at £18bn in real terms between 2010 and 2015 (36). Secondly, wellbeing is essentially social as well as individual $(3,6)$ and it is therefore important that research, policy and practice move beyond personal psychological constructs, being informed by psychosocial perspectives (20) and utilising models that incorporate individual, family, community, and societal dimensions (11). Those implementing such models must grapple with the challenge of making multi-level holistic wellbeing meaningful within a culture of growing self-interest propagated by pervasive neo-liberal ideology (12). Thirdly, wellbeing is experienced in relation to and influenced by people's contexts and surroundings (11), a finding particularly prominent for those participating in activities in natural settings and echoing the growing body of evidence concerning wellbeing and people's relationship with nature (37). Finally, there is an emerging social and ecological critique of the personal wellbeing discourse and the policy focus on individual happiness within the context of an increasingly consumerist society. As Carlisle et al. (4) highlight, this may prevent the attainment of wellbeing by others and jeopardise the future wellbeing of humanity and the planet. This suggests that it will be

Pre-Print Version: Dooris, M., Farrier, A., Froggett, L. (in press) Wellbeing: The Challenge of 'Operationalising' an Holistic Concept within a Reductionist Public Health Programme. Perspectives in Public Health. 
important to connect psychosocial models with emerging eco-social frameworks that connect social with ecological determinants of health (38).

\section{ACKNOWLEDGEMENTS}

Our thanks to all the beneficiaries and key staff involved in the Target: Wellbeing projects and programmes who participated in the research.

\section{ETHICAL APPROVAL}

A University Ethics Committee granted approval for the evaluation.

\section{FUNDING AND COMPETING INTERESTS}

This work was supported by the Big Lottery Fund [no Grant number]. There are no conflicts of interest.

\section{REFERENCES}

1. Anderson P, Cooper C, Layard R et al. Well-being and global success: a report prepared by the World Economic Forum Global Agenda Council on Health \& Well-being. (REF 100112). World Economic Forum, Geneva, Switzerland, 2012.

2. McAllister F. Wellbeing Concepts and Challenges. SDRN Briefing 2005; 3: 1-8.

3. Ryan RM and Deci EL. On happiness and human potentials: a review of research on hedonic and eudaimonic well-being. Annual review of psychology 2001; 52: 141-166.

4. Carlisle S, Henderson G and Hanlon PW. "Wellbeing": A collateral casualty of modernity? Social Science and Medicine 2009; 69, 10: 1556-1560.

5. Walker P. Wellbeing: On public health and wellbeing. In Walker P and John M (eds) From Public Health to Wellbeing: The New Driver for Policy and Action (1st ed.). Basingstoke: Palgrave Macmillan, 2012, pp. 1-20.

Pre-Print Version: Dooris, M., Farrier, A., Froggett, L. (in press) Wellbeing: The Challenge of 'Operationalising' an Holistic Concept within a Reductionist Public Health Programme. Perspectives in Public Health. 
6. Bacon N, Brophy M, Mguni N et al. The State of Happiness: Can public policy shape people's wellbeing and resilience? London: The Young Foundation, 2010.

7. World Health Organization. Basic Documents. 47th Edition, Geneva: WHO, 2009.

8. La Placa V and Knight A. Well-being: Its influence and local impact on public health. Public Health 2014; 128, 1: $38-42$.

9. Huppert F. Psychological Well-Being: Evidence Regarding its Causes and its Consequences. London: Foresight, 2009.

10. Aked J and Thompson S. Five Ways to Wellbeing: New applications, new ways of thinking. London: New Economics Foundation, 2011.

11. McNaught A. Defining wellbeing. Chapter in Knight A and McNaught A (eds) Understanding Wellbeing: An Introduction for Students and Practitioners of Health and Social Care. Banbury: Lantern, 2011.

12. Jones-Devitt S. Wellbeing and health. Chapter in Knight A and McNaught A (eds) Understanding Wellbeing: An Introduction for Students and Practitioners of Health and Social Care. Banbury: Lantern, 2011.

13. Government Office for Science. Foresight Mental Capital and Wellbeing Project. Final Project Report. London, 2008.

14. Local Government Act 2000. Local Government Act 2000. UK: The Stationary Office Limited, 2000.

15. HM Government. Healthy Lives, Healthy People: Our strategy for public health in England. London: Department of Health (Mental Health Division), 2010.

16. English Oxford Living Dictionaries https://en.oxforddictionaries.com (accessed 12 April 2017).

17. Giles S, Philips S, Timpson C et al. Target: Wellbeing Evaluation - Annual Report February 2010 (Reporting period April-September 09). Liverpool: North West Public Health Observatory, 2010.

18. Swarbrick K, Jones A and Perkins C. Target: Wellbeing Evaluation. Final Report. Liverpool: North West Public Health Observatory, 2010.

19. Lamont T, Barber N, de Pury J et al. New approaches to evaluating complex health and care systems. BMJ

Pre-Print Version: Dooris, M., Farrier, A., Froggett, L. (in press) Wellbeing: The Challenge of 'Operationalising' an Holistic Concept within a Reductionist Public Health Programme. Perspectives in Public Health. 
2016; 352: i154.

20. [Author]. Love, hate and welfare: psychosocial approaches to policy and practice. Bristol: Policy Press, 2002.

21. Abdallah S, Steuer N, Marks $\mathrm{N}$ et al. Wellbeing evaluation tools: A research and development project for the Big Lottery Fund. Final report. London: New Economics Foundation, 2008.

22. La Placa V, McNaught A and Knight A. Discourse on wellbeing in research and practice. International Journal of Wellbeing 2013; 3(1): 116-125.

23. Denzin NK and Lincoln YS. Introduction: The discipline and practice of qualitative research. In Denzin NK and Lincoln YS (eds) Strategies of qualitative inquiry. London: Sage, 2008.

24. Wilkinson S. Analysing Focus Group Data, in D Silverman (ed.) Qualitative Research (3 ${ }^{\text {rd }}$ Edition). London: Sage, 2011.

25. O'Leary Z. The Essential Guide to Doing Research. Sage, London, 2004.

26. Aked J, Marks N, Cordon C et al. Five Ways to Wellbeing: A report presented to the Foresight Project on communicating the evidence base for improving people's well-being. London: New Economics Foundation, 2008.

27. Knifton L. Collective wellbeing in public mental health, Perspectives in Public Health 2015; 135(1): 24-26.

28. Cameron E, Mathers J and Parry J. 'Health and well-being': Questioning the use of health concepts in public health policy and practice. Critical Public Health 2008;16(4): 347-354.

29. Antonovsky, A. (1996) The salutogenic model as a theory to guide health promotion 1. Health Promotion International, 11,1, 11-18.

30. Lindström B and Eriksson M. The Hitchhiker's Guide to Salutogenesis: Salutogenic Pathways to Health Promotion. Folkhälsan Research Centre Research Report 2010:2. Helsinki: Folkhälsan Research Centre, 2010. 31. Walker P and John M (eds.) From Public Health to Wellbeing: The New Driver for Policy and Action (1st ed.), Basingstoke: Palgrave Macmillan, 2012.

Pre-Print Version: Dooris, M., Farrier, A., Froggett, L. (in press) Wellbeing: The Challenge of 'Operationalising' an Holistic Concept within a Reductionist Public Health Programme. Perspectives in Public Health. 
32. Local Government Improvement and Development The role of local government in promoting wellbeing. London: LGID, 2010.

33. World Health Organization. Ottawa Charter for Health Promotion, Geneva: WHO, 1986.

34. Huppert FA, Baylis N, \& Keverne B (eds.) The science of wellbeing. Oxford: Oxford University Press, 2005.

35. Crawshaw P. 'Whither wellbeing for public health?' Critical Public Health 2008; 18(3): 259-261.

36. Gainsbury S and Neville S. Austerity’s f18bn impact on local services. Financial Times, $19^{\text {th }}$ July 2015.

(http://www.ft.com/cms/s/2/5fcbd0c4-2948-11e5-8db8-c033edba8a6e.html\#axzz4FXGTWfGA accessed 31 ${ }^{\text {st }}$ January 2017).

37. Barton J, Bragg R, Wood C et al. Green Exercise: Linking Nature, Health and Well-Being. London: Routledge, 2016.

38. Hancock T. Population health promotion 2.0: An eco-social approach to public health in the Anthropocene. Canadian Journal of Public Health 2015; 106(4): e252-e255.

Pre-Print Version: Dooris, M., Farrier, A., Froggett, L. (in press) Wellbeing: The Challenge of 'Operationalising' an Holistic Concept within a Reductionist Public Health Programme. Perspectives in Public Health. 